\title{
doispontos:
}

\section{Avicena e suas fontes: Alexandre de Afrodísia e Temístio (Parte 1)}

\author{
Avicenna and his Sources: Alexander of Aphrodisias and Themistius (Part 1)
}

\author{
Meline Costa Sousa \\ Universidade Federal de Lavras - UFLA \\ meline.sousa@ufla.br
}

\begin{abstract}
Resumo: Esse artigo faz parte de um estudo maior sobre Avicena e suas fontes tardo-antigas que visa a analisar a relação entre Avicena, Alexandre de Afrodísia e Temístio no que diz respeito ao intelecto. Há, ainda hoje, uma série de questões discutidas pelos estudiosos relativas à teoria noética de Avicena. Uma dessas questões trata da natureza do intelecto agente e da sua relação com o intelecto humano. Contudo, dada a complexidade dessa relação, as linhas que se seguem consistem na primeira parte da investigação, a qual se restringirá a uma introdução geral ao posicionamento dos três autores quanto à natureza do intelecto produtivo (ou agente). Tendo em vista as diferentes abordagens, dentre elas a identificação da posição tomada por Avicena com aquela encontrada nas obras de Alexandre de Afrodísia e Temístio, analisarei, em linhas gerais, as suas interpretações do De anima 430a10-25 quanto à caracterização e distinção dos intelectos. Por fim, discutirei algumas dificuldades apresentadas por esse tipo de abordagem da questão.
\end{abstract}

Palavras-chave: Avicena, fontes, filosofia árabe, antiguidade tardia, intelecto, recepção.

\begin{abstract}
This article is part of a more significant investigation on Avicenna and his Late Antique sources. It aims to discuss the relation between Avicenna, Alexander of Aphrodisias, and Themistius from their theory about the intellect. Nowadays, there is a long debate among the scholars concerning Avicenna's noetic theory. One of its issues is the nature of the agent intellect, and its relationship to the human intellect. However, since it is a difficult subject, the following lines are the first part of this investigation. They will be restricted to a general introduction to those three interpretations of the productive (or agent) intellect's nature. One finds an analysis of the relation between Avicenna and his Late Antique sources based on the strict association (sometimes a strong dependence) of Avicenna's theory with Alexander's and Themistius' ones. Thus, I will discuss their interpretation of Aristotle's De anima 430a10-25 concerning the description and distinction of the intellects. Then, I will indicate some difficulties related to this strict association.
\end{abstract}

Keywords: Avicenna, sources, arabic philosophy, late antiquity, intellect, reception. 


\section{Introdução}

Como apontam alguns estudos historiográficos (GUTAS, 2002, p. 10-2), uma das linhas interpretativas a partir da qual a filosofia árabe foi abordada, ao longo do século XX, teve suas bases assentadas sobre o pressuposto de que os filósofos árabes foram meros intermediários entre a filosofia grega e a filosofia latina ${ }^{1}$. Deste modo, a filosofia produzida em língua árabe foi considerada "em si, filosoficamente insignificante" (ibidem, p. 10). Um dos representantes desta linha interpretativa é De Boer, que, em seu manual dedicado à história da filosofia medieval, nega a importância filosófica das investigações em língua árabe. Segundo ele,

[... ] a filosofia islâmica sempre foi um ecletismo diretamente dependente do conjunto de obras traduzidas do grego. O curso da sua história não foi um processo de geração, mas de assimilação. Ela não se destacou por propor novos problemas nem por qualquer peculiaridade em sua tentativa de resolver os problemas já estabelecidos. Não houve nenhum importante avanço no conhecimento para se registrar. Assim, o valor da história da filosofia no Islã está relacionado à tentativa de se apropriar dos resultados do pensamento grego de modo mais compreensível e livre do que aquele realizado pelos primeiros cristãos [...] (DE BOER, 1901 apud GUTAS, 2002, p. 11)

O primeiro ponto da análise de De Boer é a negação da originalidade da filosofia árabe e, consequentemente, dos filósofos desta tradição, tal como Avicena. Conforme a sua crítica, o pensamento filosófico árabe resumese a um processo de assimilação do conteúdo estabelecido pelas traduções em língua árabe dos tratados em língua grega. Assim, os filósofos desta tradição ter-se-iam mantido presos aos princípios e problemas já estabelecidos pelos filósofos antigos sem tentar resolvê-los e sem propor novos questionamentos: "não houve nenhum importante avanço no conhecimento para se registrar" (idem).

De Boer não nega todo o valor do estudo da história da filosofia árabe. A conclusão da passagem acima reconhece a importância dessa tradição na transmissão, para o ocidente cristão, dos conteúdos extraídos dos textos gregos. Portanto, o "valor da história da filosofia no Islã está relacionado à tentativa de se apropriar dos resultados do pensamento grego de modo mais compreensível e livre do que aquele realizado pelos primeiros cristãos" (idem). Essa interpretação do pensamento árabe fundamenta-se na visão de que os semitas, especialmente os falantes de árabe, eram incapazes de produzir uma filosofia crítica e racional, mas apenas especulações místicas ${ }^{2}$.

Tal postura historiográfica não foi assumida apenas pelos historiadores da filosofia medieval latina, mas também pode ser localizada entre os historiadores da filosofia medieval árabe. O tradutor do Tahăfut alTahāfut de Averróis, Simon van den Bergh, adotou como epígrafe da sua tradução um excerto segundo o qual "Apenas os gregos filosofaram" (AVERROES, 1954 apud GUTAS, 2002, p. 11). Assim, conclui Gutas (2002, p. 11) que, "se os arabistas apresentam a filosofia árabe como derivada e filosoficamente insignificante, é fácil perceber como os outros historiadores da filosofia e, especialmente os medievalistas, estariam justificados em adotar a mesma visão".

\footnotetext{
${ }^{1}$ Embora haja uma literatura que já tenha mostrado, em linhas gerais, os problemas implícitos nesta linha interpretativa, muitos pontos da filosofia de Avicena, como, por exemplo, a teoria da emanação e a noética são reduzidos às considerações de autores da tradição em língua grega. São necessários, portanto, estudos de casos que reconstruam os fundamentos da filosofia aviceniana a partir do seu corpus, sem reduzi-los às considerações presentes nas obras de autores tais como Aristóteles, Plotino, Alexandre de Afrodísia e Temístio.

${ }^{2}$ Cf. GUTAS, 2002, p. 11.
} 
Tendo em vista a argumentação de Gutas (ibidem, p. 5-25) e alguns estudos recentes sobre recepção a afirmação segundo a qual o "curso da história [do pensamento árabe] não foi um processo de geração, mas de assimilação" (DE BOER, 1901 apud GUTAS, 2002, p. 11) é um equívoco: a) na medida em que negligencia a própria natureza do estabelecimento dos textos gregos e de sua chegada à cultura islâmica ${ }^{4} \mathrm{e}$ b) na medida em que nega a autonomia do pensamento filosófico em língua árabe. Dada a complexidade da discussão, deter-me-ei, introdutoriamente, apenas ao ponto b (a autonomia do pensamento filosófico em língua árabe). O estudo de caso que proponho, a dizer, a relação entre Avicena, Alexandre de Afrodísia e Temístio ${ }^{5}$ no que diz respeito à distinção entre os intelectos produtivo e passivo, tem em vista ilustrar, ainda que de modo breve e a partir de um recorte temático específico, a transformação ${ }^{6}$ realizada por Avicena das suas fontes gregas. Ao contrário da interpretação de alguns estudiosos ${ }^{7}$, o posicionamento adotado por Avicena quanto à natureza dos intelectos não pode ser reduzido ao conteúdo das suas fontes. Ele está diretamente ligado, como sugere Lizzini (2016, p. 285), ao modelo metafísico aviceniano.

Os autores da antiguidade tardia já se dividiam acerca da distinção entre os intelectos apresentada no De anima 430a10-258 e o tipo de relação mantida entre eles. Nesta passagem, Aristóteles distingue dois intelectos, um que produz todas as coisas e outro que vem a ser todas as coisas. Tal distinção é apresentada a partir de um raciocínio fundamentado na relação causa-causado. Como todos os outros entes naturais em potência, o intelecto que vem a ser todas as coisas precisa de uma causa em ato que o faça passar do estado de potência ao de ato. Porque esta causa é um intelecto em ato, ele é responsável pela atualização

${ }^{3}$ Budelmann e Haubold (2008, p. 24-5) analisam os conceitos de recepção e tradição, apontando a existência de uma dependência direta entre eles na medida em que, ao vincular os dois conceitos, tradição deixa de ter o sentido de algo acabado, pronto. Trata-se, antes, de uma concepção artificial, um recorte a posteriori, algo construído, fabricado, inventado. Compreender o conceito de tradição diretamente vinculado à recepção permite que se estabeleçam conexões entre diferentes contextos. Como sugere Martindale (1993, p. 4-5), uma tradição é construída e analisada do ponto de vista da recepção de um determinado texto ou conjunto de textos. Trata-se, portanto, de um quadro ou recorte das recepções de um dado autor realizado em um período específico. Segundo Martindale (1993, p. 5), “[...] qualquer noção que envolva a ideia de um puro encontro entre texto e leitor, o qual seria um tipo de tabula rasa, é absurda. Todos nós lemos um texto com a bagagem dada pelos nossos valores e nossa experiência, com certas categorias, pressupostos e preconceitos. Possuir esta bagagem é próprio do ser humano na história; sem ela não poderíamos ler de modo algum".

${ }^{4}$ Segundo Sgarbi (2012, p.x), "Olhar a história das ideias a partir do ponto de vista da translatio studiorum significa enfatizar as rupturas, as rejeições e a transformação da linguagem, conceitos e problemas no interior das tradições específicas [...] Escrever a história de uma tradição, incluindo sua linguagem, conceitos e problemas envolve não apenas reconhecer elementos intelectuais comuns, mas também identificar elementos novos e originais na tradição ela mesma”.

${ }^{5}$ Embora outros autores do mesmo período tenham discutido sobre o intelecto agente a partir da passagem aristotélica mencionada, como, por exemplo, Teofrasto de Eresa, Estefano de Alexandria, Filopono, Simplício, dentre outros, menciono apenas Temístio e Alexandre de Afrodísia porque ambos consideraram ser o intelecto agente uma substância separada, influenciando a interpretação adotada pelos autores da tradição árabe. Cf. BOBBA, 1896; GRABMANN, 2006; JOLIVET, 1997, p. 569-82; SHROEDER, 1990; BLUMENTHAL, 1996; ENDRESS, 2002, p. 19-74; FINAMORE, 2011; MORAUX, 1978, p. 281-324; MAGRIN, 2011, p. 49-74.

${ }^{6}$ Como sugere Perler (2009, p. 2), o termo "transformação" exprime bem a relação entre os autores medievais e os textos de Aristóteles na medida em que não se trata de uma simples continuidade de um modelo já existente, nem de uma ruptura que propõe algo radicalmente diferente, mas de um longo processo caracterizado pelo surgimento de algo novo a partir do que já existia.

${ }^{7}$ Cf. BOBBA, 1896, p. 265; DAVIDSON, 1992, p. 13; MAGRIN, 2011, p. 49. Alguns estudiosos referem-se apenas à filosofia árabe em geral. Outros mencionam explicitamente os nomes de alguns filósofos como, por exemplo, Avicena e Averróis. Essa interpretação será discutida mais adiante.

${ }^{8}$ A passagem indicada é o único momento do De anima no qual Aristóteles trata, em detalhes, da distinção entre o intelecto que vem a ser todas as coisas e o intelecto que produz todas as coisas. Cf. ARISTOTLE, 1961; BLUMENTHAL, 1996, p. 312-24; BOBBA, 1896; DE CORTE (1934); IVRY, 2001, p. 59-77; JOLIVET, 1997, p. 569-582; RIST, 1966, p. 8-20; PERLER, 2009; MONTADA, 2007, p. 129-35; LLOYD, OWEN, 1978; NUSSBAUM, RORTY, 1992. O texto grego do De anima foi consultado a partir da edição de Ross (1961, p. 133-4) e o texto árabe a partir da tradução anônima editada por Badawi (1954, p. 74). 
do outro intelecto. Contudo, a passagem não é clara acerca do tipo de distinção, ou seja, se se trata de duas substâncias diferentes ou se são dois princípios que compõem a mesma substância, nem acerca de como o intelecto que produz todas as coisas é causa da atualização do outro intelecto.

Tendo em vista a análise feita por alguns estudiosos ${ }^{9}$, ainda que Alexandre, Temístio e Avicena divirjam acerca do estatuto ontológico do intelecto material, todos concordam com a "interpretação transcendente" (DAVIDSON, 1992, p. 13) do intelecto agente. Assim, a posição de Alexandre de Afrodísia seria a de considerar o intelecto agente como uma "substância separada, causa primeira" (SELLES, 2006, p. 1393) ou poder externo (MAGRIN, 2011, p. 66-7) sempre em ato e, por isto, divino e imortal. O intelecto material seria apresentado como "pura disposição ou aptidão para receber as formas de tal modo que não se identifica com nenhuma delas" (DAVIDSON, 1992, p. 9). Já a posição de Temístio estabeleceria não apenas que o intelecto agente é uma substância separada da alma humana, mas também o intelecto possível, o qual seria "não misturado com o corpo, impassível e separado" (idem).

O De intellectu ${ }^{10}$ de Alexandre de Afrodísia, o qual segue a estrutura de um epítome, foi traduzido para o árabe (século IX) na escola de Hunayn Ibn Ishāq em Bagdá, da qual também fazia parte o filho Ishāa Ibn Hunayn (o que gera certa confusão em torno da autoria da tradução ${ }^{11}$ ). Alexandre ${ }^{12}$ apresenta o intelecto produtivo ou agente ( 'aql $f a$ " 'âl) ${ }^{13}$ como o intelecto por meio do qual o intelecto material ('aql hayūlānī $)^{14}$ passa a intelecto em ato ('aql bi-l-fi l l) ${ }^{15}$.

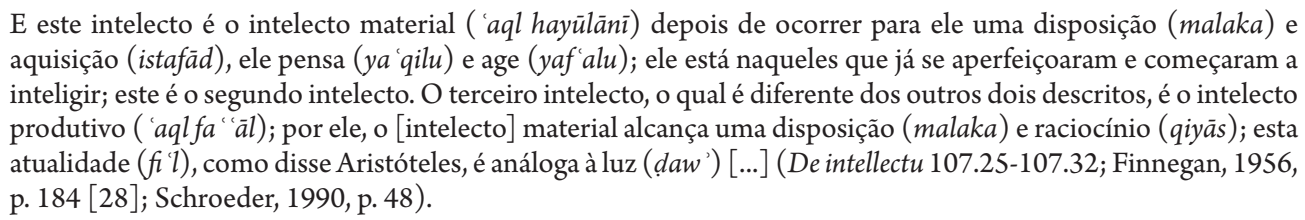

Do ponto de vista teórico, o primeiro intelecto, descrito como hílico ou material, caracteriza-se pela capacidade de pensar qualquer forma. Por não ser uma faculdade corpórea, cuja atividade dependeria de um órgão localizado no corpo, o intelecto material se identifica com as formas inteligíveis. Neste sentido, o termo material é utilizado em analogia com a passividade da matéria ${ }^{16}$. A partir do momento em que esse intelecto pensa em ato, ele deixa de ser uma potência absoluta. Embora, na passagem acima, se encontre a expressão "segundo intelecto", não se trata de outra faculdade, mas de diferentes fases ou momentos do mesmo intelecto.

\footnotetext{
${ }^{9}$ Cf. BOBBA, 1896, p. 265; DAVIDSON, 1992, p. 13; MAGRIN, 2011, p. 49; TAYLOR, 2013, p. 3. Averróis também é mencionado pelos estudiosos como tendo herdado de Alexandre de Afrodísia e de Temístio o estatuto do intelecto agente. Cf. TAYLOR, 2013, p. 3.

${ }^{10} \mathrm{O}$ De intellectu faz parte de uma coleção de escritos sobre a alma intitulada Mantissa. A partir de agora, utilizarei a edição árabe de Finnegan (1956, p. 181 [24] -199 [43]) e a tradução inglesa de Schroeder (1990, p. 45-57). Cf. ACCATINO, 2014, p. 275.

${ }^{11}$ Cf. SCHROEDER; TODD, 1990, p. 2, n.5. Sobre as versões dos textos de Alexandre no círculo de al-Kindi, ver FAZZO, WIESNER, 1993, p. 119-53.

${ }^{12}$ De intellectu 106.19-110.3; Finnegan, 1956, p. 181 [24]-189 [33]; Schroeder, 1990, p. 46-51.

${ }^{13}$ Cf. De intellectu 107.29-30; Finnegan, 1956, p. 184 [28]; Schroeder, 1990, p. 48.

${ }^{14}$ Cf. De intellectu 106.19; Finnegan, 1956, p. 181 [24]; Schroeder, 1990, p. 46. Finnegan (1956b, p. 198) considera que o uso do termo material, para se referir ao intelecto, teria sido primeiramente proposto por Alexandre.

${ }^{15}$ Cf. De intellectu 108.6-7; Finnegan, 1956, p. 185 [29]; Schroeder, 1990, p. 48.

${ }^{16} \mathrm{Um}$ dos pontos da crítica de Avicena diz respeito à associação entre o intelecto em potência e a matéria. Como mostra Gutas (2004, p. 82), Avicena entende que o intelecto material segundo a interpretação de Alexandre de Afrodísia seria efetivamente material.
} 
Por fim, é mencionado o intelecto produtivo, o qual consiste na causa eficiente da intelecção realizada pelo intelecto material. A ação deste intelecto produtivo é identificada com a atualidade da luz mencionada por Aristóteles no De anima 430a10-25. Segundo a interpretação de Alexandre ${ }^{17}$, do mesmo modo que a luz é causa de as cores que são potencialmente visíveis tornarem-se cores visíveis em ato, o intelecto produtivo (ou agente) faz com que o intelecto em potência (ou material) venha a ser intelecto em ato ${ }^{18}$ ao transformar as formas inteligíveis em potência em formas inteligíveis em ato.

Uma das primeiras características elencadas ${ }^{19}$ para o intelecto produtivo é o fato de ele ser exterior à alma humana e, por isto, não ser idêntico a nenhuma das suas faculdades, embora ele "venha a existir em nós" (De intellectu 108.24; Finnegan, 1956, p. 186 [30]; Schroeder, 1990, p. 49) no momento em que pensamos. Deste modo, ele existe separado dos homens e da matéria ${ }^{20}$, sendo imperecível $(\underline{t} a \overline{b i t})^{21}$. No De intellectu' ${ }^{22}$, ele é descrito como uma forma (șüra) que, diferentemente de todas as outras formas que são pensadas pelo intelecto humano ${ }^{23}$, não se identifica com este durante a intelecção.

Segundo Schroeder (1997, p. 105), o intelecto produtivo contribui diretamente para a formação do intelecto humano ao lhe servir como forma e como "objeto do pensamento antes do engajamento da mente humana com a informação sensível” (idem). No entanto, porque ele se encontra eternamente em ato, inteligirá apenas a si mesmo, mantendo-se simples e imaterial (i.e., não misturado com o corpo). Aquii ${ }^{24}$ a argumentação fundamenta-se no princípio aristotélico segundo o qual um intelecto simples não pode inteligir nada que seja diferente de si mesmo, caso contrário isso multiplicaria a sua natureza.

A identidade entre intelecto, intelecção e inteligível salvaguarda a simplicidade do intelecto produtivo. Embora Alexandre não mencione, no De intellectu, o que seria o intelecto produtivo, alguns estudiosos ${ }^{25}$ tomam o uso do adjetivo "divino" ('ilāhī) ${ }^{26}$ e algumas características atribuídas a ele (i.e., absoluta

\footnotetext{
${ }^{17}$ De intellectu 107.29-34; Finnegan, 1956, p. 184 [28]; Schroeder, 1990, p. 48.

${ }^{18}$ Segundo Alexandre de Afrodisia (De intellectu 111.15-6 apud TAYLOR, 2016, p. 275): "[...] o intelecto, ao apreender a forma da coisa que é pensada e separá-la da matéria, torna-a um inteligível em ato e a si mesmo um intelecto em ato [...]”.

${ }^{19}$ De intellectu 108.19-108.26; Finnegan, 1956, p. 186 [30]; Schroeder, 1990, p. 49.

${ }^{20}$ Cf. De intellectu 108.26-7; Finnegan, 1956, p. 186 [30]; Schroeder, 1990, p. 49. Como aponta Fazzo e Wiesner (1993, p. 121), para Alexandre há uma interação entre estas substâncias celestes, separadas e imortais e as substâncias sublunares. Contudo, dado o caráter fragmentário do tratamento da interação entre elas, Alexandre não possui uma teoria integral desta "interação dinâmica".

${ }^{21}$ Cf. De intellectu 108.31; Finnegan, 1956, p. 187 [31]; Schroeder, 1990, p. 49.

${ }^{22}$ De intellectu 108.29; Finnegan, 1956, p. 186 [30]; Schroeder, 1990, p. 49.

${ }^{23}$ Segundo Alexandre de Afrodísia (De intellectu 108.4-7 apud TAYLOR, 2016, p. 275): “[...] as formas materiais são tornadas inteligíveis pelo intelecto, sendo, antes, inteligíveis em potência. O intelecto separa a forma da matéria com a qual elas existem e, ele mesmo, as torna inteligíveis em ato; e cada uma delas, quando pensada, torna-se um inteligível em ato [...]”.

${ }^{24}$ De intellectu 109.27-109.31; Finnegan, 1956, p. 189 [33]; Schroeder, 1990, p. 51.

${ }^{25}$ Cf. CASTON, 1999, p. 201; SELLES, 2006, p. 1393; TAYLOR, 2016, p. 274; MAGRIN, 2011, p. 66; FREDE, 1996, p. 383-4; BOERI, 2009, p. 80-1. Para Blumenthal (1987, p. 94), o intelecto em ato mencionado por Aristóteles em III.5, segundo a leitura de Alexandre, é a causa suprema de todas as coisas, ou seja, "identifica-se com o primeiro movente aristotélico". Ao comparar a interpretação da passagem 430a10-25 proposta por Temístio com a interpretação proposta por Alexandre, Todd (1990, p. 32) afirma que Temístio rejeitou a identificação do intelecto produtivo (ou agente) com Deus tal como proposto por Alexandre no De intellectu.
}

${ }^{26}$ Cf. De intellectu 112.16; Finnegan, 1956, p. 196 [40]; Schroeder, 1990, p. 56. 
simplicidade $^{27}$, imortalidade ${ }^{28}$, causa ${ }^{29}$, existência separada $\left.{ }^{30}\right)$ como indicativos de se tratar de Deus ou do Primeiro Princípio.

Temístio, na sua Paráfrase do De anima ${ }^{31}$, traduzida para o árabe por Ishāq Ibn Hunayn ${ }^{32}$, afirma (sem mencionar o nome de Alexandre de Afrodísia $\left.{ }^{33}\right)$ :

Com relação aos que compreenderam por intelecto produtivo ( 'aql fa "äl) o Deus primeiro ('allāh al-'awwal), por que ignoraram o que se segue nesta mesma passagem [430a10-25]? Após dizer, primeiro, que em toda natureza (kull al-tabī'a) existe uma coisa que é matéria (hayūlā) e outra coisa que move (yuharriku) a matéria e a completa (yatimmuhā), ele disse que deve ser necessário que essas diferenças existam na alma [...] (Paráfrase do De anima 102.36-103.2; Lyons, 1973, p. 186.16-187.1; Todd, 1990, p. 102).

Nesta passagem, o primeiro ponto é negar que o intelecto produtivo ou agente, o qual teria sido apresentado por Aristóteles em 430a10-25, se identifique com o "Deus primeiro". A distinção entre as partes que compõem os entes naturais, ou seja, a matéria e "outra coisa que move a matéria e a completa", é considerada existindo também na alma e não fora dela. Como, na alma, há um intelecto que vem a ser todas as coisas e um intelecto que produz todas as coisas, este não pode ser Deus, uma substância completamente diferente da alma humana. Assim, Temístio ${ }^{34}$ identifica, em III.5, a distinção entre três tipos distintos de intelectos e não apenas dois: o intelecto produtivo ou agente (' $a q l f a$ " 'al), o intelecto material ou em potência ('aql alladī bi-l-quwa) e o intelecto passivo ou comum ('aql muštarak) ${ }^{35}$. O intelecto produtivo, que existe em completo ato, dada sua perfeição natural, completa o intelecto possível, tornando-se unido a ele na medida em que aquele é uma forma ou "a forma das formas" (Paráfrase do De anima 100.33; Lyons, 1973, p. 182.18; Todd, 1990, p. 95); neste aspecto, a posição de Temístio assemelha-se à de Alexandre. No entanto, elas são diferentes com respeito ao fato de, para o primeiro, o intelecto produtivo ser uma faculdade da alma humana.

Segundo Martin (1966, p. 3), o filósofo depara-se com a dificuldade de estabelecer se o intelecto em potência é impassível (gayr munfa 'il), tal como o agente ${ }^{36}$, ou corruptível (fäsid), tal como o passivo ${ }^{37}$. A interpretação de Temístio da natureza dos intelectos em potência e produtivo considera estarem ambos os intelectos na alma

${ }^{27}$ Cf. De intellectu 109.27-109.31; Finnegan, 1956, p. 189 [33]; Schroeder, 1990, p. 51.

${ }^{28}$ Cf. De intellectu 108.31; Finnegan, 1956, p. 187 [31]; Schroeder, 1990, p. 49.

${ }^{29}$ Cf. De intellectu 111.34; Finnegan, 1956, p. 194 [38]; Schroeder, 1990, p. 55.

${ }^{30}$ Cf. De intellectu 108.26-7; Finnegan, 1956, p. 186 [30]; Schroeder, 1990, p. 49.

${ }^{31}$ Lyons (1955, p. 426) não se refere a ele como uma paráfrase, mas como um comentário. A partir de agora, utilizarei a edição árabe de Lyons (1973) e a tradução inglesa de Todd (1990, p. 77-133).

${ }^{32}$ Cf. LYONS, 1955, p. 426; 430; BADAWI, 1954, p. 14-5; ELAMRANI-JAMAL, 2003, p. 348; GUERRERO, 1992, p. 93.

${ }_{33}^{33}$ Alguns estudiosos (cf. Todd, 1990, p. 102, n.113) reconhecem ser a crítica de Temístio direcionada a Alexandre, pois este teria identificado o intelecto agente com Deus.

${ }_{34}^{34}$ Paráfrase do De anima 105.13-105.34; Lyons, 1973, p. 191.9-192.11; Todd, 1990, p. 108-9.

${ }^{35}$ Temístio (Paráfrase do De anima 105.13-105.34; Lyons, 1973, p. 191.9-192.11; Todd, 1990, p. 108-9) considera haver um terceiro intelecto chamado intelecto comum, o qual é perecível, passivo e misturado com o corpo. Tendo em vista o escopo deste artigo, não entrarei em detalhes acerca deste intelecto. Sobre o intelecto passivo e sua relação com a imaginação e o corpo, ver Martin (1966, p. 17-8).

${ }^{36}$ Cf. Paráfrase do De anima 101.4; Lyons, 1973, p. 183.8; Todd, 1990, p. 95.

${ }^{37}$ Cf. Paráfrase do De anima 101.4; Lyons, 1973, p. 183.8; Todd, 1990, p. 95. 
humana $^{38}$, embora sejam separados. Aristóteles teria considerado o intelecto em potência como sendo eterno, separado e capaz de receber formas sem, antes de as receber, vir a ser qualquer uma delas ${ }^{39}$.

Contudo, o que significa dizer que o intelecto produtivo é imortal, eterno e separado ${ }^{40}$ ? A resposta parece estar vinculada ao fato de ele não ser misturado com o corpo que, ao receber uma forma, torna-se determinado por ela. Como aponta Taylor (2013, p. 16), o intelecto é essencialmente eterno ainda que os inteligíveis, nele, sejam corruptíveis “devido à conexão com as formas na imaginação". Trata-se, portanto, de não sofrer nenhum tipo de alteração decorrente da mistura com o corpo, tal como os sentidos sofrem. Assim, o intelecto (seja ela produtivo ou possível) é separado do corpo, mas não da alma humana.

No entanto, é importante salientar que, embora ambos os intelectos compartilhem algumas propriedades, tais como serem impassíveis e separados, eles não compartilham a mesma natureza ${ }^{41}$. A distinção entre eles se baseia no fato de o intelecto produtivo estar, essencialmente, em ato e o intelecto em potência, essencialmente, em potência. A superioridade do intelecto produtivo é estabelecida pelo princípio aristotélico segundo o qual a causa é mais perfeita do que o causado ${ }^{42}$.

II

Antes de apontar alguns problemas relativos à abordagem mencionada na introdução, cabe mencionar o posicionamento de Avicena acerca da distinção entre os intelectos ${ }^{43}$. Embora não se tenha acesso ao seu comentário ${ }^{44}$ ao De anima III.5 430a10-25, a interpretação aviceniana acerca da distinção entre os intelectos ${ }^{45}$ pode ser identificada no Livro sobre a alma V.5. A partir da distinção causal entre o princípio ativo, o qual ocupa a posição de causa eficiente para uma dada atualização, e o princípio passivo, no qual se dá a atualização, passando de um estado de potência ao de ato, Avicena distingue, na alma humana, dois estágios ou fases: um momento no qual ela é inteligente em potência e outro no qual ela é inteligente em

\footnotetext{
${ }^{38}$ A imanência do intelecto agente na alma é consequência da união entre os intelectos agente e em potência. Cf. MARTIN, 1966 , p. $8 ; 10-2$.

${ }^{39}$ Essa é a interpretação de Temístio (Paráfrase do De anima 105.34-106.7; Lyons, 1973, p. 192.8-192.18; Todd, 1990, p. 109) do que Aristóteles teria dito. Segundo Martin (1966, p. 4), as características atribuídas ao intelecto em potência são: não estar em ato antes de conhecer e não possuir nenhuma forma, embora capaz de receber qualquer forma.
}

${ }^{40}$ Cf. Paráfrase do De anima 102.35; Lyons, 1973, p. 186.16; Todd, 1990, p. 101.

${ }^{41}$ A interpretação de Martin (1966, p. 4) vai em outra direção. Segundo o estudioso, o intelecto em ato e o intelecto em potência não são dois intelectos separados, mas são dois estágios de um mesmo intelecto.

${ }^{42}$ Segundo Temístio (Paráfrase do De anima 106.7-10; Lyons, 1973, p. 192.16-193.2; Todd, 1990, p. 108-9): “[Aristóteles] considerou ser evidente que todos os dois [intelectos] são separados, porém o produtivo é dos dois o mais intensamente separado, e dos dois é o mais distante da alteração e da mistura. Quanto ao tempo, o intelecto em potência vem a ser anterior em nós, enquanto por natureza e por perfeição o intelecto produtivo é anterior”.

${ }^{43}$ Para uma análise completa, ver Sousa, 2018, p. 9-24.

${ }^{44}$ Não se tem acesso ao comentário de Avicena ao De anima, mas apenas às suas Notas. Aqui, utilizarei o Livro sobre a alma (Kitāb al-nafs) V.5, o qual foi escrito por Avicena em meados do século XI e faz parte dos seus escritos dedicados às investigações naturais. Não se trata de um comentário à obra homônima de Aristóteles. Cf. GUTAS, 2004, p. 78. Sobre a recepção em língua árabe do De anima, ver SOUSA, 2018, p. 9-15.

${ }^{45}$ Como mostrarei, Avicena distingue entre um intelecto humano, ou seja, que faz parte das faculdades da alma que é própria dos homens, e um intelecto celeste que é separado e independente do intelecto humano. 
ato $^{46}$. Tendo em vista ser o intelecto uma das faculdades da alma humana que, como a matéria (hayūlā), está em potência para receber qualquer forma e, com isto, conhecer, constata-se que deve existir algo que atualize esta potência. A necessidade deste elemento é concluída a partir do seguinte raciocínio: tudo que passa da potência ao ato depende de um princípio ativo; as almas humanas passam da potência ao ato; logo, as almas humanas dependem de um princípio ativo.

Afirmar que o intelecto se torna inteligente em ato significa dizer que ele intelige formas inteligíveis em ato de modo que a atualização do intelecto está diretamente relacionada à aquisição de formas inteligíveis. Assim, faz-se necessária essa causa agente que doe certo tipo de forma inteligível para o intelecto e "ela não é outra coisa que um intelecto agente no qual existem as formas inteligíveis puras" (K. al-nafs V.5, p. $234^{47}$ ). Contudo, Avicena não considera tratar-se de dois princípios imanentes à alma racional, pois o intelecto agente é uma substância separada da alma humana.

Sob a perspectiva da teoria da emanação $0^{48}$, modelo por meio do qual o filósofo explica a criação e a origem da multiplicidade, a discussão acerca do intelecto agente é deslocada para o âmbito da filosofia primeira.

É necessário que os intelectos separados ( 'aqūl mufäriqa), ou melhor, o último deles que está próximo de nós ${ }^{49}$ seja isto da qual emana (yufị̈u), com a participação (mušāraka) dos movimentos celestes (harikāt samāwiyya), uma coisa na qual se encontra a impressão (rasm) das formas (șuwar) do mundo inferior ('älam 'asfal) de modo passivo (infi 'äl), assim como naquele intelecto ou intelectos se encontram os traços destas formas de modo ativo (taf'iyl). Deste modo, as formas emanam dele [...] (Ilāhīyyāt IX.5, 410.6-410.9; Marmura, 2005, p. 335; Bertolacci, 2008, p. 751).

Os intelectos celestes, dentre os quais Avicena insere o intelecto agente, participam da emanação (fayḍ) a partir da qual, do primeiro princípio, indiretamente decorrem todos os existentes. A criação, entendida como um ato eterno e único, é diferenciada de outro tipo de conferir existência do qual o intelecto agente faz parte $^{50}$. Este sentido de conferir existência, aqui, é especialmente ilustrativo na medida em que o primeiro

\footnotetext{
${ }^{46}$ Sobre as fases ou estágios do intelecto de acordo com o Livro sobre a alma (Kitāb al-nafs I.5, p. 47-50; McGinnis and Reisman, 2007, p. 184-5; Attie, 2011, p. 70-2), no caso do intelecto em potência ou material, trata-se da disposição ilimitada para inteligir sem que nenhuma forma tenha sido adquirida como, por exemplo, o bebê e a escrita. Segundo Davidson (1992, p. 84), ao nascer, a alma humana não realizou nenhum pensamento e possui meramente uma potencialidade para pensar. Com o crescimento da criança, esta potencialidade se desenvolve de modo que Avicena distingue uma série de estágios, os quais começam com a pura potencialidade. Em seguida, tem-se o intelecto em hábito. Ele é o intelecto potencial após ter recebido os primeiros inteligíveis. Por isto, Avicena atribui a ele a expressão potência possível; neste caso, o intelecto já possui os princípios a partir dos quais pode conhecer, tal como o jovem que conheceu o tinteiro, a pena e o alfabeto. $\mathrm{O}$ intelecto em ato é caracterizado pela aquisição em ato de novos inteligíveis, embora, naquele momento, ele não se dedique a eles: "chama-se intelecto em ato porque ele é um intelecto que intelige quando quer sem se obrigar a uma nova obtenção” (idem), como quando o jovem já aprendeu a escrever, mas, naquele momento específico, não está escrevendo. A última relação é a perfeição absoluta do intelecto, chamada intelecto adquirido. O grau de intelecto adquirido consiste na posse em ato das formas inteligíveis que, naquele momento, são conhecidas em ato.

${ }^{47}$ Cf. Bakosh, 1956, p. 166; McGinnis and Reisman, 2007, p. 199; Attie, 2011, p. 242.

${ }^{48}$ Sobre a emanação cf. LIZZINI, 2011, p. 27-36.

${ }^{49}$ I.é, o intelecto agente.

${ }^{50}$ 'Ibdā' é um termo que possui dois significados: 1- a realização de uma coisa, não a partir de outra coisa, nem por mediação de outra coisa; 2 - seu segundo significado é que uma coisa possui existência absoluta a partir de uma causa, sem mediação, e à essência desta coisa pertence o fato de ela não ser um existente, mas o que lhe pertence essencialmente está em um perfeito modo removido. Cf. Risala al-hudüd 105 [70]; Goichon, 1963, p. 60.
} 
princípio não cria a multiplicidade sublunar ${ }^{51}$, mas todos os existentes são originados por emanação a partir do intelecto agente. Tanto a multiplicidade supralunar, cuja necessidade da existência é causada por meio da autointelecção, quanto a sublunar, cuja presença no substrato material estabelece a pluralidade dos indivíduos, adquirem existência por meio deste fluxo ${ }^{52}$. Neste modelo emanacionista, o intelecto agente não seria apenas o dator formarum ${ }^{53}$, i.e., o princípio eficiente responsável pela existência das substâncias sublunares, como também a matriz de certos inteligíveis para o intelecto material.

Para alguns estudiosos ${ }^{54}$, porque foi o intelecto agente que fez originar no mundo as formas materiais ${ }^{55}$, é apenas com a sua ajuda que o intelecto humano consegue abstraí-las completamente na medida em que "brilha sobre elas a luz do intelecto agente" (K. al-nafs V.5, p. $234^{56}$ ). Contudo, dada a complexidade da relação entre o intelecto humano e as formas inteligíveis, é importante salientar que, devido aos diferentes tipos de inteligíveis e às diferentes atividades realizadas pelo int electo ${ }^{57}$, reduzir todos os processos do intelecto à simples iluminação do intelecto agente parece não ser compatível com o texto aviceniano ${ }^{58}$.

${ }^{51}$ A cosmologia árabe se vale do sistema de esferas celestes, as quais são organizadas em uma hierarquia descendente de perfeição. A mais perfeita esfera, chamada de primeiro céu, é mais nobre que as outras esferas da hierarquia. Abaixo desta está a esfera das estrelas fixas, caracterizada pelas estrelas estarem imóveis. Em seguida, estão as esferas dos planetas, cuja ordem é: primeira esfera, a mais próxima da Terra, é ocupada pela Lua; a segunda por Mercúrio; a terceira por Vênus; a quarta pelo Sol; a quinta por Marte; a sexta por Júpiter e a sétima por Saturno. Esta ordem foi estabelecida por Ptolomeu. Assim, a última esfera é a esfera que gira em torno da esfera dos quatro elementos e da Terra. Das nove esferas, sete contêm planetas, uma contém estrelas e uma não contém nem planetas, nem estrelas. Os outros existentes que compõem o âmbito supralunar são os dez intelectos celestes (onze para Farabi). Cf. JANOS, 2009, p. 117-8; 133.

${ }^{52}$ A multiplicidade se amplia com o emanar dos intelectos uns dos outros, pois cada nova inteligência intelige a si, as anteriores e o existente necessário. Um ponto importante, aqui, é que o existente necessário cria, diretamente, apenas da primeira inteligência já que ele não lida, diretamente, com a multiplicidade dos existentes. Segundo Colish (1975, p. 299), ao adotar a teoria da emanação, Avicena resolve parte da dificuldade retirando de Deus a tarefa de criar a multiplicidade, contudo, faz-se necessário recorrer às causas secundárias, dentre elas o intelecto agente, para continuar a cadeia hierárquica de emanação.

${ }^{53}$ Cf. Física I.10, 3.4; McGinnis, 2009, p. 65. Ver, DAVIDSON, 1992, p. 78.

${ }^{54}$ Segundo Davidson (1992, p. 93): "Avicena empregou a analogia com a visão porque ela tinha se tornado comum, mas, no todo, ela não se adéqua bem. Sua posição não é que a emanação do intelecto agente capacita o intelecto humano a abstrair conceitos a partir das imagens apresentadas pela faculdade imaginativa; assim como quando se veem as cores que são iluminadas pelos raios do sol. Pensamentos inteligíveis emanam diretamente do intelecto agente e não são abstraídos de modo algum.” Sobre outros estudiosos que assumiram uma interpretação semelhante, ver Hasse (2013, p. 109).

${ }^{55}$ Segundo Lizzini (2016, p. 288), a intelecção realizada pelo intelecto humano é a recepção de formas emanadas do intelecto agente. Sobre o fato de a forma inteligível emanada do intelecto agente ser a responsável pela identificação entre forma universal e forma particular cf. MCGINNIS, 2007, p. 165-86.

${ }^{56}$ Cf. Bakosh, 1956; p. 166; McGinnis and Reisman, 2007, p. 199; Attie, 2011, p. 242.

${ }^{57}$ Segundo o Livro sobre a alma V.3, há três modos de conceitualização por meio dos quais o intelecto, em conjunto com os sentidos internos, adquire formas inteligíveis. O primeiro modo é descrito como a ordenação das intenções em uma proposição sem que a ordem seja necessária, formulando, assim, premissas empíricas. Embora Avicena afirme que ela é realizada pela substância incorpórea, os sentidos a auxiliam na medida em que eles fornecem os sujeitos com os quais o intelecto lida. O segundo modo de conceitualização acontece quando o intelecto já realizou a primeira conceitualização, mas abandonou as intenções adquiridas a fim de conceitualizar outras. O terceiro e último modo parece referir-se ao momento no qual o intelecto recupera as intenções que já foram conceitualizadas, mas que, em um determinado momento, foram abandonadas. Em seguida, o intelecto assente à verdade ou à falsidade da proposição; em outras palavras, ele investiga a causa de se atribuir determinada intenção a um sujeito. Isto apenas é possível após a conceitualização dos particulares e a intuição dos termos médios do silogismo. Como a causa é o termo médio do silogismo que é adquirido por intuição ou por instrução, o intelecto não é capaz de concluir o assentimento sem ele. A intuição é um processo imediato de recebimento do que é emanado do intelecto agente. Cf. HASSE, 2001, p. 39-82; GUTAS, 2012, p. 391-436; 2001, p. 1-38.

${ }^{58}$ Segundo Gutas (2012a, p. 420), a relação entre intelecto agente e humano é descrita de dois modos: do ponto de vista do intelecto agente ou do ponto de vista do intelecto humano. No primeiro caso, o processo de recepção dos termos médios é chamado de "emanação divina" (idem), caracterizado pela emanação dos inteligíveis sobre o intelecto; da perspectiva do intelecto humano, o processo é descrito como a intuição ou o aprendizado do termo médio, sendo uma busca que está dentre as disposições do homem. 
Portanto, como Avicena adota uma explicação da criação que se vale de intermediários ${ }^{59}$, os quais emanam do mais perfeito até chegar ao intelecto agente do qual emanam as formas no mundo, o intelecto mencionado por Aristóteles no De anima III.5 430a10-25, que é a causa eficiente da produção de todas as coisas, é o intelecto agente separado e não misturado; o intelecto que está em potência é o intelecto material (ou humano) que, embora seja independente do corpo ${ }^{60}$, está vinculado a ele na medida em que precisa dos sentidos ${ }^{61}$ para conhecer.

\section{III}

Tal como mencionado no início do artigo, o acesso que os filósofos árabes, dentre eles Avicena, tiveram a alguns textos antigos e a semelhança entre os seus posicionamentos levaram muitos estudiosos ${ }^{62}$ a considerá-los adeptos da tradição tardo-antiga ao interpretarem a passagem aristotélica (III.5 430a10-25). A partir dos indícios ${ }^{63}$ da influência de Alexandre de Afrodísia e de Temístio na filosofia medieval árabe, recorreu-se às interpretações destes dois autores a fim de justificar as considerações avicenianas acerca do intelecto agente ${ }^{64}$. Contudo, nem sempre se trata do reconhecimento das possíveis origens da discussão herdada pelos autores da tradição árabe a partir das traduções e paráfrases dos textos de Alexandre e de Temístio. Um dos pressupostos assumidos é o de que, nas duas tradições (grega e árabe), a compreensão do intelecto que produz todas as coisas é a mesma. Essa tentativa de pensar a influência da tradição filosófica grega sobre a filosofia árabe apresenta algumas deficiências com respeito ao entendimento das particularidades da transformação que Avicena faz do tratado aristotélico ${ }^{65}$. Não se trata de negar que os textos de Alexandre e Temístio tenham sido fontes lidas por Avicena (o que é assumido pelo próprio filósofo $\left.{ }^{66}\right)$. Como aponta Gutas (2004, p. 81-2), nas Notas ao De anima, Avicena refere-se criticamente a Temístio e a Alexandre de Afrodísia, apresentando argumentos contrários às suas interpretações. Assim, o diálogo que Avicena mantém com a tradição aristotélica não pode ser utilizado para provar que a sua leitura tenha sido determinada pelas interpretações dos dois autores. Como afirma Lizzini (2016, p. 290), teorias epistemológicas árabes, dentre elas a de Avicena, "não podem ser explicadas apenas com base nas suas fontes".

O fato de, no Livro sobre a alma V.5, o intelecto agente ser assumido como uma substância separada não é uma compreensão exclusiva dos textos de Alexandre de Afrodísia e Temístio. Pelo contrário, trata-se de uma conclusão extraível da própria passagem do De anima de Aristóteles na qual se encontram os adjetivos

\footnotetext{
${ }^{59}$ Stricto sensu, o termo criação aplica-se apenas ao ato de conferir existência que o primeiro princípio realiza, por emanação, relativo à primeira inteligência.

${ }^{60}$ Sobre a independência da alma racional cf. HASSE 2000, p. 80-92.

${ }^{61}$ Os sentidos externos compõem as faculdades perceptivas da alma animal juntamente com os sentidos internos. Deste modo, a ação própria dos sentidos externos é perceber. São eles: tato, visão, paladar, audição e olfato. O segundo tipo de percepção é realizado pelos cinco sentidos internos que se distinguem dos sentidos externos por realizarem percepções a partir de dentro. São eles: sentido comum, imaginação retentiva, imaginativa, no homem chamada cogitativa, faculdade estimativa, e memória, caracterizados pelo fato de as formas materiais e as intenções percebidas ainda serem determinadas quantitativamente e qualitativamente. Cf. WOLFSON, 1935, p. p. 69-133; DI MARTINO, 2008; PORMANN, 2013, p. 91-108.

${ }^{62}$ BOBBA, 1896, p. 265; FINNEGAN, 1956b, p. 192; DAVIDSON, 1992, p. 13; MAGRIN, 2011, p. 49; TAYLOR, 2013 , p. 3.

${ }^{63}$ Segundo Gutas (2004, p. 81-2), Avicena menciona, nas Notas ao De anima, os nomes de Alexandre de Afrodísia (quatro vezes) e Temístio (duas vezes). Assim, a conexão entre Avicena e a tradição de comentadores gregos é estabelecida pelo próprio filósofo.

${ }^{64}$ Sobre o intelecto possível ou material, cf. FINNEGAN, 1956b, p. 198-9.

${ }^{65}$ Para mais detalhes acerca da relação entre a filosofia aviceniana e a tradição aristotélica, ver Gutas (2014 [1998]).

${ }^{66}$ Cf. GUTAS, 2004, p. 81.
} 


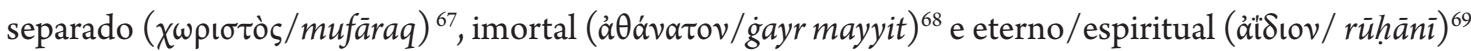
em referência ao intelecto. Neste sentido, as semelhanças entre as interpretações discutidas se justificam tendo em vista o fato de todas se construírem a partir da mesma passagem aristotélica.

No caso de Alexandre, a peculiaridade da sua interpretação encontra-se no modo pelo qual o intelecto produtivo é abordado. Ao descrevê-lo no De intellectu, em diversos momentos ${ }^{70}$, o filósofo se refere a ele como uma forma. Neste sentido, haveria certa união substancial ${ }^{71}$ entre este intelecto e o intelecto humano, possibilitando, assim, a atualização da disposição humana para inteligir. Esses dois aspectos do intelecto produtivo, a saber, ser uma forma e se unir ao intelecto humano, estão diretamente relacionados. Tendo em vista o vínculo entre os elementos que constituem os pares forma/matéria e ato/potência, haveria uma ligação necessária entre os intelectos produtivo e material. Porque a atividade de inteligir se dá em um substrato em potência (matéria) que chega ao ato por causa de um princípio agente (forma), pressupõe-se a união entre eles.

A especificidade da posição de Temístio sobre o intelecto produtivo relaciona-se ao fato de ele ser uma faculdade da alma humana: "nós somos o intelecto produtivo" (Paráfrase do De anima 101.1; Lyons, 1973, p. 183.5; Todd, 1990, p. 95). Ainda que, na Paráfrase do De anima, ele seja dito separado, não se trata, no entanto, de uma separação substancial. Temístio, diferentemente de Alexandre, assume tal termo como significando a independência de qualquer órgão corpóreo. Assim, como apontado anteriormente, o intelecto produtivo ou agente é separado do corpo, embora não esteja separado do homem, o que faz dele uma faculdade da alma racional.

Portanto, do fato de os três autores defenderem o mesmo estatuto ontológico para o intelecto agente, não decorre que eles possuam a mesma compreensão da natureza do intelecto que produz todas as coisas. Como aponta Davidson (1992, p. 14), Alexandre lê o De anima III.5 em vista da distinção substancial presente na Metafísica XII, considerando ser o intelecto que produz todas as coisas a substância incorruptível e causa primeira, ou seja, Deus. No caso de Temístio, o intelecto em questão também possui uma natureza transcendente, mas, diferentemente do caso anterior, não se trata de uma substância distinta da alma humana.

Deste modo, as características mencionadas, as quais vão além do reconhecimento do intelecto agente como separado (termo que não assume o mesmo sentido nos textos de Alexandre e Temístio), não são encontradas no Livro sobre a alma de Avicena. Neste, a substância considerada transcendente ${ }^{72}$ não é uma forma nem uma faculdade da alma humana. Tendo em vista que o intelecto material é uma das faculdades da alma humana que, como a matéria, está em potência para receber qualquer forma, faz-se necessária uma causa que forneça alguns inteligíveis para o intelecto e "ela não é outra coisa que um intelecto agente no qual existem as formas inteligíveis puras” ( $K$. al-nafs V.5, p. 234 $4^{73}$ ). Assim, o intelecto agente não é apenas causalmente diferenciado do intelecto humano como também é uma substância ontologicamente diferenciada. A adoção, por parte de Avicena, de um modelo criacionista que se vale de intelectos celestes como intermediários, sendo o último deles o intelecto no qual as formas inteligíveis se encontram todas em ato, levou-o a considerar o intelecto produtivo de III.5 como um intelecto celeste e, por isto,

\footnotetext{
${ }^{67}$ De anima III.5 430a17; Ross, 1961, p. 133; Badawi, 1954, p. 74.

${ }^{68}$ De anima III.5 430a23; Ross, 1961, p. 134; Badawi, 1954, p. 74.

${ }^{69} \mathrm{Idem}$.

${ }^{70}$ De intellectu 108.24; 108.29; 108.31; Finnegan, 1956, p. 186 [30]-187 [31]; Schroeder, 1990, p. 49

${ }^{71}$ Cf. FINNEGAN, 1956b, p. 193. O termo utilizado na tradução árabe é aquisição, a partir do qual se tem o intelecto adquirido.

${ }^{72}$ Segundo Lizzini (2016, p. 285), "a transcendência atribuída ao intelecto separado pode ser explicada pela teoria da emanação, a qual é a fundação das suas metafísicas [de Farabi e Avicena]”.

${ }^{73}$ Cf. Bakosh, p. 166; McGinnis and Reisman, p. 199; Attie, p. 242.
} 
ontologicamente separado do intelecto material. Porque o intelecto agente é a última substância celeste a participar da origem da multiplicidade, ele é causa da existência das formas e almas no mundo sublunar, âmbito ontológico ${ }^{74}$, e causa eficiente da intuição do intelecto humano ao fornecer termos médios para ele, âmbito epistemológico.

Embora fuja ao escopo deste artigo, outro problema de reduzir a filosofia árabe às suas fontes é o fato de não conseguirmos explicar, por exemplo, as distinções teóricas no interior da própria tradição. Ainda que o intelecto agente para Avicena e Averróis (no Grande Comentário ao De anima) possua o mesmo estatuto ontológico, suas abordagens não são as mesmas. Em outras palavras, se essas interpretações em língua árabe de 430a10-25 pudessem ser compreendidas a partir das fontes gregas, não haveria nenhuma distinção entre as teorias noéticas de Avicena e de Averróis. Neste sentido, os problemas de reduzir a interpretação de Avicena às fontes devem-se ao fato de essa abordagem ser incapaz de apontar: a) o modo pelo qual Avicena transforma o De anima 430a10-25, b) a natureza do intelecto que produz todas as coisas e do intelecto que vem a ser todas as coisas e c) por que Avicena adota a separação substancial entre os intelectos.

\section{Referências bibliográficas:}

1) Edições

ARISTOTLE. 1961. De anima. Ed. David Ross, New York: Oxford University Press.

BADAWI, A. 1954. Aristutalis fi al-nafs. Cairo: Maktabat al-Nahda al-Misriyya.

FINNEGAN, J. 1956. Texte arabe du Peri nou d'Alexandre d'Aphrodise. Beyrouth: Imprimerie Catholique.

IBN SINA. 1959. Kitāb al-nafs. Edited by F. Rahman. London: Oxford University Press, 1959.

LYONS, M. C. 1973. An Arabic Translation of Themistius Commentary on Aristoteles De anima. Columbia, South Carolina: University of South Carolina Press.

2) Traduções

ARISTOTELE. 2008. L'anima. Trad. Giancarlo Movia. Milano: Bompiani.

AVICENA. 2011. Livro da alma. Trad. M. Attie Filho. São Paulo: Editora Globo.

AVICENNA. 2008. Libro della Guarigione. Le Cose Divine. Trad. A. Bertolacci. Torino: UTET.

AVICENNA. 2002. Metafisica. Trad. Olga Lizzini, Milano: R.C.S. Libri S.p. A.

AVICENNA. 2009. The Physics of The Healing. Trad. J. McGinnis, Utah: Brigham Young University Press.

\footnotetext{
${ }^{74}$ Por conseguinte, enquanto fruto da intelecção divina da qual fluem os existentes, Lizzini (2011, p. 320) aponta a proeminência do momento noético em detrimento do ontológico. Nada acontece sem que o Primeiro Princípio intelija a si mesmo. Contudo, trata-se de uma anterioridade que se mantém "aporética" devido à sua concomitância temporal com a dimensão ontológica. Porque a intelecção de si é contínua, o fluxo de existência também é: "não apenas a intelecção é criação, mas a existência do Primeiro consiste na sua própria autointelecção" (idem). É propriamente esta circularidade em torno do processo que marca a unidade fundamental dele.
} 
AVICENNE. 1963. Livre des Définitions. Ed. Trad. A. M. Goichon. Caire: Institut Français d’Archeologie Orientale du Caire.

AVICENNE. 1956. Psychologie d’Ibn Sinnā. Ed. et trad. J. Bakosh. Praga: Académie Tchécoslovaque des Sciences.

MCGINNIS, J., REISMAN, D. C. (eds). 2007. Classical Arabic Philosophy. An Anthology of Sources. Indianapolis/Cambridge: Hackett Publishing Company, Inc., p. 175-209.

SHROEDER, F. M., TODD, R. B. (eds). 1990. Two Greek Aristotelian Commentators on the Intellect. Canada: Pontifical Institute of Mediaeval Studies.

3) Outras referências

ACAR, R. 2004. Avicenna's position concerning the basis of the divine creative action. The Muslim World, 94, 1, p. 65-79.

ADAMSON, P. (ed). 2013. Interpreting Avicenna. Cambridge: Cambridge University Press.

ADAMSON, P., TAYLOR, R. C. (eds). 2005. The Cambridge Companion to Arabic Philosophy. Cambridge: Cambridge University Press.

ARIF, S. 2000. Intuition and its Role in Ibn Sina's Epistemology. Journal of the International Institute of Islamic Thought and Civilization, 5, 1, p. 95-126.

BAZAN, B. C. 1981. Intellectum Speculativum: Averroes, Thomas Aquinas, and Siger Brabant on the Intelligible Object. Journal of the History of Philosophy, 19, 4, p. 425-446.

BERTOLACCI, A. 2002. The doctrine of Causality in the Ilähiyyāt of Avicenna's Kitäb al-Shifä̀' Q Quaestio, 2, p. 125-154.

BLACK, D. 2013. Rational Imagination: Avicenna on the Cogitative Power. In: TELLKAMP, J., LÓPEZ, X. F. (eds). Philosophical Psychology in Medieval Arabic and Latin Aristotelianism. Paris: J. Vrin, p. 59-81.

BLUMENTHAL, H.J. 1987. Alexander of Aphrodisias in the later Greek commentaries on Aristotle's De Anima. In: NUTTON, V., KOLESH, J., LULOFS, H.J., WIESNER, J. (eds.), Kommentierung, Überlieferung, Nachleben. De Gruyter, p. 90-106.

BLUMENTHAL, H.J. 1996. Aristotle and Neoplatonism in Late Antiquity: Interpretations of the De Anima. London: Cornell University Press.

BOBBA, R. 1896. La dottrina dell'intelletto in Aristotele i nei suoi più illustri interpreti. Turin: Clausen.

BROWNE, G. M. 1986. Ad Themistium arabum. Illinois Classical Studies, 11, p. 223-45.

BROWNE, G. M. 1998. Ad Themistium arabum II. Illinois Classical Studies, 23, p. 121-26.

CASTON, V. 1999. Aristotle's Two Intellects: A Modest Proposal. Phronesis, 44, 3, p. 199-227. 
COLISH. M. L. 1975. Avicenna's Theory of Efficient Causation and its Influence on St. Thomas Aquinas. In: Tommaso d'Aquino nella storia del pensiero. Atti del Congresso Internazionale (Roma-Napoli 17/24 aprile 1974): Tommaso d'Aquino nel suo settimo centenario. Napoli, p. 296-306.

COSTA, C. D., SERRA, G. (2002). Aristotele E Alessandro di Afrodisia Nella Tradizione Araba Atti Del Colloquio la Ricezione Araba Ed Ebraica Della Filosofia E Della Scienza Greche, Padova, 14-15 Maggio 1999.

DAVIDSON, H. A. 1992. Alfarabi, Avicenna, and Averroes, on Intellect. New York: Oxford University Press.

DE BOER, S. W. 2013. The Science of the Soul. The Commentary Tradition on Aristotle's De anima, c. 12601360. Leuven: Leuven University Press.

DE CORTE, M. 1934. La doctrine de V intelligence chez Aristote, Essai d'exégèse. Paris: Vrin.

DE CORTE, M. 1935. La dottrine dell'intelligence chez Aristote, Paris: Vrin.

DI MARTINO, C. 2008. Ratio Particularis. La doctrine des sens internes d'Avicenne à Thomas d'Aquin. Paris: J. Vrin.

ENDRESS, G. 2002. Alexander Arabus on the First Cause: Aristotle's First Mover in an Arabic Treatise Attributed to Alexander of Aphrodisias. [Editor?] Aristotele e Alessandro di Afrodisia nella tradizione araba. Padova: Il poligrafo, p. 19-74.

FAZZO, S., WIESINER, H. 1993. Alexander of Aphrodisias in the Kindi Circle and in al-Kindi's Cosmology. Arabic Sciences and Philosophy, 3, 1, p. 119-53.

FINAMORE, J. 2011. Colloquium 1: Themistius on Soul and Intellect in Aristotle's De Anima. Proceedings of the Boston Area Colloquium of Ancient Philosophy, 26, 1, p. 1-23.

FINNEGAN, J. 1956. Texte arabe du Peri nou d'Alexandre d'A phrodise. Beyrouth: Imprimerie Catholique.

FINNEGAN, J. 1956b. Avicenna's Refutation of Porphyrius. Avicenna Commemoration Volume, Calcutta, p. 187-203.

FREDE, M. 1996. La théorie aristotélicienne de l'intellect agent. In: DHERBEY, R., VIANO, C. (eds.). 1996. Corps et Âme: sur le De anima d'Aristote. Paris: J. Vrin, p. 377-390.

FRYDE, E. B. 1994. The 'Paraphrase' by Themistios of Aristotle's De Anima, and St Thomas Aquinas, The English Historical Review, CXI, 433, p. 952-959.

GOICHON, A. M. 1938. Lexique de la Langue Philosophique d'Ibn Sina. Paris: Desclée de Brower.

GRABMANN, M. 2006. Interpretações Medievais do Nous Poietikós. Campinas: IFCH/Unicamp.

GUERRERO, R. R. 1992. La recepción árabe del De Anima de Aristóteles: Al-Kindi y Al-Farabi. Madrid: Consejo Superior de Investigaciones Cientificas.

GUTAS, D. 2001. Intuition and Thinking: The Evolving Structure of Avicenna's Epistemology”. In: WISNOVSKY, R. (ed). Aspects of Avicenna. Princeton: Princeton Press, p. 1-38. 
GUTAS, D. 2002. The Study of Arabic Philosophy in the Twentieth Century. An Essay on the Historiography of Arabic Philosophy. British Journal of Middle Eastern Studies, 29, p. 5-25.

GUTAS, D. 2004. Avicenna's Marginal Glosses on De anima and the Greek Commentatorial Tradition. Bulletin of the Institute of Classical Studies. Supplement, 83, p. 77-88.

GUTAS, D. 2012a. Avicenna: The Metaphysics of the Rational Soul. The Muslim World, 102, p. 417-25.

GUTAS, D. 2012b. The Empiricism of Avicenna. Oriens, 40, p. 391-436.

GUTAS, D. 2013. Avicenna's Philosophical Project. In: ADAMSON, P. (ed). 2013. Interpreting Avicenna. Cambridge: Cambridge University Press, p. 28-47.

GUTAS, D. 2014 [1988]. Avicenna and the Aristotelian Tradition. Leiden-Boston: E. J. Brill.

HARDWICK, L.; STRAY, C. 2008. A Companion to Classical Receptions. New York: Blackwell Publishing Ltd.

HASSE, D. N. 2001. Avicenna on Abstraction. In: WISNOVSKY, R. (ed.). Aspects of Avicenna. Princeton: Princeton Press, p. 39-82.

HASSE, D. N. 2013. Avicenna's Epistemological Optimism. In: P. ADAMSON, P. (ed). Interpreting Avicenna. Cambridge: Cambridge University Press, p. 109-119.

HASSE, D. N. Avicenna's De anima in the Latin West. London/Turin: The Warburg Institute, 2000.

HENDRIX, J. S. 2010. Philosophy of Intellect and Vision in the De anima and De intellectu of Alexander of Aphrodisias. School of Architecture, Art, and Historic Preservation Faculty Papers, 15, p. 1-29.

IVRY, A. 2001. The Arabic Text of Aristotle’s De anima and Its Translator. Oriens, 36, p. 59-77.

JANOS, D. 2009. Intellect, Substance, and Motion in al-Farabi's Cosmology. PhD, McGill University.

JOLIVET, J. 1997. Étapes dans l'histoire de l'intellect agent. In: HASNAWI, A., ELAMRRANI-JAMAL, A., AOUAD, M. (eds.). Perspectives arabes et médiévales sur la tradition scientifique et philosophique grecque. Louvain-Paris: Peeters, p. 569-582.

KOSMAN, L. 1992. What does the Maker Mind Make? In: NUSSBAUM, M., RORTY, A. (eds). Essays on Aristotle's De Anima. Oxford: Clarendon Press, p. 343-358.

LIZZINI, O. 2011. Fluxus. Indagine sui fondamenti della metafisica e della fisica di Avicenna. Bari: Edizioni di Pagina.

LIZZINI, O. 2015. Human Knowledge and Separate Intellect. In: TAYLOR, R. C.; LOPEZ-FARJEAT, L. X. The Routledge Companion to Islamic Philosophy. London-New York: Routledge, p. 285-300.

LLOYD, G., OWEN, G. (eds). 1978. Aristotle on Mind and the Senses. Cambridge: Cambridge University Press.

LOPEZ-FARJEAT, L. X, TELLKAMP, J. A. (eds). 2013. Philosophical Psychology in Arabic Thought and the Latin Aristotelianism of the 13th Century. Paris: J. Vrin. 
LYONS, M. C. (ed.). 1973. An Arabic Translation of Themistius Commentary on Aristoteles De anima. Oxford: Cassirer.

Lyons, M. C. 1955. An Arabic Translation of the Commentary of Themistius. Bulletin of the School of Oriental and African Studies, University of London, 17, 3, p. 426-435.

MAGRIN, S. 2011. Theophrastus, Alexander and Themistius on Aristotle De anima III.4-5. In: WISNOVSKY, R., WALLIS, F., FUMO, J. C., FRAENKEL, C. (eds.). Vehicles of Transmission, Translation, and Transformation in Medieval Textual Culture. Turnhout: Brepols Publishers, p. 49-74.

MARTIN, S. B. 1966. The Nature of the Human Intellect as it is Expounded in Themistius' Paraphrasis in Libros Aristotelis de Anima. In: ADELMAN, F. J. (ed) The Quest for the Absolute. Boston College Studies in Philosophy. Spring, Dordrecht, p. 1-21.

MARTINDALE, C. 1993. Redeeming the Text. Latin Poetry and the Hermeneutics of Reception. Cambridge: Cambridge University Press.

MCGINNIS, J. 2010. Avicenna. New York: Oxford University Press.

MCGINNIS, J. 2013. New Light on Avicenna, Optics and Its Role in Avicennian Theories of Vision, Cognition and Emanation. In: LÓPEZ-FARJEAT, L. X., TELLKAMP, J. A. (eds.). Philosophical Psychology in Arabic Thought and the Latin Aristotelianism of the 13th Century. Paris: Vrin, p. 41-57.

MORAUX, P. 1978. Le De anima dans la tradition grecque. Quelques aspects de l'interprétation du traité, de Théophraste à Thémistius. In: LLOYD, G., OWEN, G. (Eds.) Aristotle on Mind and the Senses: Proceedings of the Seventh Symposium Aristotelicum, Cambridge: Cambridge University Press, p. 281-324.

PERLER, D. (ed). 2009. Transformations of the Soul: Aristotelian Psychology, 1250-1650. Leiden and Boston: Brill.

PORMANN, P. E. 2013. Avicenna on Medical Practice, Epistemology, and the Physiology of the Inner Senses. In: ADAMSON, P. (ed). Interpreting Avicenna. Cambridge: Cambridge University Press, p. 91-108.

SCHROEDER, F. M. 1997. The Provenance of the De Intellectu attributed to Alexander of Aphrodisias. Documenti E Studi Sulla Tradizione Filosofica Medievale, 8, p. 105-120.

SELLES, J. F. 2006. La crítica tomista a la interpretación griega y neoplatónica del intelecto agente. [Editor?] Intellect et imagination dans la Philosophie Médiévale, Actes du XIe Congrès International de Philosophie Médiévale de la Société Internationale pour l'Étude de la Philosophie Médiévale (S.I.E.P. M.), Porto, 2631- août-2002, Brepols, vol. III, p. 1389-1404.

SGARBI, M. (ed). 2012. Translatio Studiorum: Ancient, Medieval and Modern Bearers of Intellectual History. Leiden: Brill.

SHARPLES, R. W. 2004. Alexander of Aphrodisias: What is a Mantissa? Bulletin of the Institute of Classical Studies. Supplement, 83, p. 51-69.

SOUSA, M. C. 2015. Os processos de aquisição dos termos do silogismo segundo a investigação noética de Avicena. Kriterion, 131, 2015, p. 25-44. 
SOUSA, M. C. 2016. As definições de alma segundo o Kitab al-Nafs de Avicena: os limites de três definições em vista da sua substancialidade. Analytica, 20, 1, p. 83-110.

SOUSA. M. C. 2018. As versões em língua árabe do De anima de Aristóteles. Philosophica, Lisboa, 51, p. 9-24.

SOUSA, M. C. 2019. Sobre a substancialidade da alma. Parte 2. Revista Reflexões, ano 8, n. 14, p. 80-95.

TAYLOR, R. 2013. Themistius and the Development of Averroes' Noetics. In: FRIEDMAN, R. L., COUNET, J-M. (eds.) Medieval Perspectives on Aristotle's De Anima. Louvain: Peeters Publishers, p. 1-38.

TAYLOR, R. 2016. The Epistemology of Abstraction. In: TAYLOR, R. C.; LOPEZ-FARJEAT, L. X. The Routledge Companion to Islamic Philosophy. London-New York: Routledge, p. 273-84.

TAYLOR, R. C.; LOPEZ-FARJEAT, L.X. 2016. The Routledge Companion to Islamic Philosophy. LondonNew York: Routledge.

TELLKAMP, J., LÓPEZ, X. F. (eds). 2013. Philosophical Psychology in Medieval Arabic and Latin Aristotelianism. Paris: J. Vrin.

WISNOVSKY, R., WALLIS, F., FUMO, J. C., FRAENKEL, C. (eds). 2011. Vehicles of Transmission, Translation, and Transformation in Medieval Textual Culture. Turnhout-Belgium: Brepols Publishers.

WOLFSON, H. A. 1935. The Internal Senses in Latin, Arabic and Hebrew Philosophic Texts. Harvard Theological Review, Vol. XXVIII, No. 2, p. 69-133.

Recebido em 01 de julho de 2020. Aceito em 22 de fevereiro de 2021. 